\title{
Seed maturation and post-harvest ripening negatively affect arabidopsis somatic embryogenesis
}

\author{
Han $\mathrm{Wu}^{1,2} \cdot$ Baojian Chen ${ }^{2,3} \cdot$ Martijn Fiers $^{2} \cdot$ Justyna Wróbel-Marek $^{4} \cdot$ Jan Kodde $^{2}$ - Steven P. C. Groot ${ }^{2}$. \\ Gerco Angenent ${ }^{2,3} \cdot$ Hui Feng ${ }^{1} \cdot$ Leónie Bentsink ${ }^{5} \cdot$ Kim Boutilier $^{2}$ (I)
}

Received: 16 April 2019 / Accepted: 20 June 2019 / Published online: 7 August 2019

(c) The Author(s) 2019

\begin{abstract}
Plant development is highly malleable, as evidenced by the ability of cultured cells, tissues and organs to regenerate into whole plants in vitro. The ability of plants to regenerate in vitro is influenced by many different factors, including the donor plant growth conditions and the type of explant. Empirical trial and error manipulation of these and other culture parameters is the basis for improving plant regeneration protocols, but the mechanisms underlying the effects of these parameters on plant regeneration are unknown. Somatic embryogenesis (SE) is a type of in vitro plant regeneration where somatic/vegetative cells are induced to form embryos. Here we show that seed maturation is one of the parameters that affects the ability of germinating embryos to undergo auxin-induced somatic embryogenesis in Arabidopsis thaliana. Late maturation stage seeds harvested from yellow siliques have a higher capacity for somatic embryogenesis than seeds harvested later from brown siliques, a process that can be mimicked by post-harvest storage. Physiological and genetic analyses suggest that an oxidizing environment and $\mathrm{ABA}$ metabolism enhance the rate at which germinating embryos lose capacity to reactivate embryogenic growth. Our data suggest that there is a narrow window during late seed maturation in which embryogenic competence is reduced, and that this process also takes place, albeit more slowly, during seed storage. This knowledge provides a framework for identifying new plant totipotency factors and for directing efficient SE in systems that make use of mature seed explants.
\end{abstract}

\section{Key Message}

The ability of germinating arabidopsis seeds to undergo 2,4-D-induced somatic embryogenesis is negatively influenced by in planta and post-harvest seed maturation.

Keywords Arabidopsis $\cdot$ ABA $\cdot$ Auxin $\cdot$ Post-harvest ripening $\cdot$ ROS $\cdot$ Seed maturation $\cdot$ Somatic embryogenesis

Communicated by Sergio J. Ochatt.

Han Wu and Baojian Chen have contributed equally to this work.

Electronic supplementary material The online version of this article (https://doi.org/10.1007/s11240-019-01658-8) contains supplementary material, which is available to authorized users.

Hui Feng

fenghuiaaa@263.net

$\triangle$ Kim Boutilier

kim.boutilier@wur.nl

1 College of Horticulture, Shenyang Agricultural University, Shenyang, China

2 Bioscience, Wageningen University and Research, Wageningen, The Netherlands

$\begin{array}{ll}\text { Abbreviations } \\ \text { Arabidopsis } & \text { Arabidopsis thaliana (L.) Heynh } \\ \text { 2,4-D } & \text { 2,4-Dichlorophenoxyacetic acid } \\ \text { RH } & \text { Relative humidity } \\ \text { ROS } & \text { Reactive oxygen species } \\ \text { SE } & \text { Somatic embryogenesis }\end{array}$

3 Laboratory for Molecular Biology, Wageningen University and Research, Wageningen, The Netherlands

4 Department of Cell Biology, University of Silesia in Katowice, Katowice, Poland

5 Laboratory for Plant Physiology, Wageningen University and Research, Wageningen, The Netherlands 


\section{Introduction}

Plant are able to undergo many types of regeneration, including the natural process of tissue and organ regeneration after wounding, and induced regeneration of organs and embryos in vitro (Ikeuchi et al. 2016). These various plant regeneration systems are applied widely for commercial plant breeding and propagation (Bridgen et al. 2018; Dwivedi et al. 2015), and also provide novel systems to understand how plant cells can be redirected toward new developmental fates (Kareem et al. 2016; Horstman et al. 2017).

The efficiency of plant regeneration in tissue culture is influenced by many parameters, including the plant genotype, the type of explant and the tissue culture conditions. As such, different genotypes and explants often require different plant growth and culture conditions to induce efficient regeneration. In essence, these different parameters reflect and impinge on inherent differences in the explant at the epigenetic, genetic, and physiological level (Bensen 2000; Grafi 2004; Lowe et al. 2006; Motte et al. 2014; Arrillaga et al. 2019). For example, plant tissues or explants that are developmentally young and still undergoing, or capable of reinitiating, cell proliferation are generally more responsive than developmentally older or differentiated tissues and explants (Bonga 2017). Likewise, the endogenous levels of plant hormones in a given explant can also influence in vitro regeneration capacity (Hisano et al. 2016; Grzyb et al. 2017). In most cases, the mechanistic basis for the different responses of genotypes and explants to plant growth and culture parameters is not known.

Somatic embryogenesis (SE) is one type of plant regeneration, in which embryos develop from the vegetative tissues of the plant rather than from fusion of an egg and sperm cell (Fehér 2015; Méndez-Hernández et al. 2019). SE has been studied extensively in Arabidopsis thaliana (arabidopsis), where it can be induced in vitro from many different cell types and explants, such as protoplasts, zygotic embryos, meristems and ovules (Wójcikowska and Gaj 2016; Horstman et al. 2017). Most arabidopsis SE systems use 2,4-dichlorphenoxyacetic acid (2,4-D) to induce somatic embryo development, which is either applied alone or in combination with one or more abiotic stresses, including osmotic, heavy metal ion and dehydration stress (Luo and Koop 1997; Ikeda-Iwai et al. 2002, 2003; Kobayashi et al. 2010). As in other plants, the efficiency of somatic embryo induction depends on many parameters, including the explant and the genetic background. For example, the efficiency and productivity of somatic embryo induction from immature zygotic embryos can be very high, with up to $80 \%$ of the embryos forming somatic embryos (Gaj 2004), while that of mature embryos from dry seeds is much lower, around $20 \%$, although mature seeds of some ecotypes are highly efficient in somatic embryo culture (Kobayashi et al. 2010). An extensive molecular-genetic network of chromatin modifying proteins, transcription factors and their downstream hormone pathway genes regulate arabidopsis SE (Horstman et al. 2017) but the mechanisms driving differences in explant and genotype competence for SE has not been investigated.

Here we identify a donor plant growth parameter that affects 2,4-D-induced SE from germinating arabidopsis embryos. We show that physiological aging, either during seed development or post-harvest, has a negative effect on SE from germinating embryos. Our findings define a new window during seed maturation in which the capacity to reinitiate embryogenic growth post-germination is gradually reduced.

\section{Materials and methods}

\section{Plant materials}

The following mutant alleles and reporter lines were used in this study: nced6-1/nced9-1 (Lefebvre et al. 2006), cyp707a1-1 and cyp707a2-1 (Kushiro et al. 2004), aba21 (Leon-Kloosterziel et al. 1996); ENODL4:GFP (Li et al. 2014) and WOX2:NLS-YFP (Breuninger et al. 2008). All mutant alleles and reporter lines are in the Col-0 background. All seeds used in a given experiment were derived from plants grown and harvested at the same time.

\section{Plant growth conditions}

Seeds were sown onto rock wool plugs (Grodan) moistened with $1 \mathrm{~g} / \mathrm{L}$ 6.5-6-19 fertilizer (Hyponex) and stratified at $4{ }^{\circ} \mathrm{C}$ for 2 days before they were placed in a growth chamber $(70 \%$ relative humidity, $16-\mathrm{h}$ photoperiod $(150$ $\mu \mathrm{mol} \mathrm{m} \mathrm{m}^{-2} \mathrm{~s}^{-1}$ ) at $20^{\circ} \mathrm{C}$. Plants were watered 2 times per week with $1 \mathrm{~g} / \mathrm{L}$ Hyponex. Unless stated otherwise, seeds were harvested in the following way: watering was stopped when the first few siliques started to turn yellow and the seeds were harvested 4-5 days later, with or without drying at 30\% RH (ftp://ftp.arabidopsis.org/home/tair/ABRC/ abrc_plant_growth.pdf), and then stored at $-80^{\circ} \mathrm{C}$, room temperature (RT, $20{ }^{\circ} \mathrm{C}$ ) or $4{ }^{\circ} \mathrm{C}$, as indicated. We also used WT and mutant seeds from plants grown under different light intensities and temperatures (Supplemental Table 1) that were stored for 5 years at either $-80{ }^{\circ} \mathrm{C}$ or on the lab bench at RT (He et al. 2014). 


\section{Somatic embryo culture}

The SE culture protocol was modified from published protocols (Mordhorst et al. 1998; Kobayashi et al. 2010). Seeds were surface-sterilized with $70 \%$ ethanol for $1 \mathrm{~min}$, followed by $2 \%$ bleach for $20 \mathrm{~min}$ and then washed with double-distilled water four times before transfer to $30 \mathrm{ml}$ of 1/2MS-10 medium (half-strength Murashige and Skoog macro and micro elements and vitamins (Duchefa) (Murashige and Skoog 1962), 1\% (w/v) sucrose, pH 5.8) containing $1 \mu \mathrm{M}$ 2,4-D, dissolved with sodium hydroxide and diluted with double-distilled water, in $190 \mathrm{ml}$ containers (Greiner). Approximately 60-100 seeds per container were used. The seeds were stratified at $4{ }^{\circ} \mathrm{C}$ in the dark for 2 days and then placed on a rotary shaker $(130 \mathrm{rpm})$ and cultured on $16 \mathrm{~h} / 8 \mathrm{~h}$ day/night cycle $\left(100 \mu \mathrm{mol} \mathrm{m}^{-2} \mathrm{~s}^{-1}\right)$ at $25^{\circ} \mathrm{C}$. The number of seedlings with embryogenic tissue or bipolar somatic embryos was counted after 2 weeks of culture. Three or more replicates with at least 60 seedlings/replicate were performed per experiment.

\section{Seed treatments}

For the high oxygen storage experiment, seeds from yellow siliques were dried at 30\% RH and stored in transparent $194 \mathrm{ml}$ glass jars with a metal lid and plastisol sealing at 99\% oxygen. The RH of the jars was ca. 30\%, which was achieved by adding $40 \mathrm{~g}$ of silica gel (Bartolotta et al. 1991; Groot et al. 2012) that was dried to $30 \%$ RH. Seeds were placed in a paper bag in the jar, and the jars were flushed with oxygen $(2 \mathrm{~min}$ at $0.5 \mathrm{~L} / \mathrm{min})$ through a hole in the metal lid, which was then closed with self-adhesive aluminium tape (Griffon). The oxygen levels in the jars were tested at least $20 \mathrm{~min}$ after closure by means of PreSens optical oxygen sensor dots (Precision Sensing $\mathrm{GmbH}$ ) placed inside each jar. The jars were placed at $20{ }^{\circ} \mathrm{C}$ for the indicated time period. The equilibrium $\mathrm{RH}(\mathrm{eRH})$ of small seeds/small samples could not be accurately measured, therefore, the eRH of the silica gel was used as an indirect measure of seed eRH. The eRH of the silica gel at the end of the experiment was $30 \%( \pm 1.0)$ and was determined by measuring the water activity (aw) (Rotronic, Switzerland) and then multiplying the aw by 100 to obtain the eRH.

The indicated concentrations of $\mathrm{H}_{2} \mathrm{O}_{2}$ (VWR Chemicals) and $\mathrm{ABA}$ (mixture of \pm stereoisomers; Sigma; dissolved in DMSO) (Duchefa) were added to the SE culture medium prior to stratification and left for the duration of the culture.

\section{Quantitative RT-PCR}

RNA was isolated using the RNeasy PowerPlant kit (Qiagen), treated with DNase to remove remaining DNA using the TURBO DNA-free ${ }^{\mathrm{TM}}$ kit (Invitrogen) and then used for
cDNA synthesis with the iScript cDNA synthesis kit (BioRad). Quantitative real-time RT-PCR was performed using a BioRad MyiQ PCR machine and SYBR green (BioRad). The primers are shown in Supplemental Table 2. The relative gene expression level was calculated according to the $2^{-\Delta \Delta C_{T}}$ method (Livak and Schmittgen 2001) using aged seeds as the calibrator and SAND (Czechowski et al. 2005) as the reference gene.

\section{Microscopy}

For confocal analysis, seedlings were embedded in $0.2 \%$ agarose containing $10 \mu \mathrm{M}$ FM4-64 (Invitrogen) (de Folter et al. 2007) and imaged with a Leica SPE DM5500 upright confocal microscope using the LAS AF 1.8.2 software. YFP/ GFP and FM4-64 were excited with a 488 and 532-nm solidstate laser, respectively, and emissions were detected at band widths of 500-530 and 617-655 nm, respectively.

\section{Results}

\section{Somatic embryogenesis from mature seeds}

The SE protocol presented here is a modified version of the protocol by Kobayashi et al. (2010), which uses 2,4-dichlorophenoxyacetic acid $(2,4-\mathrm{D})$ as the inducer and handexcised embryos from germinated seeds as explants. We simplified the protocol by germinating and culturing Col- 0 arabidopsis seeds continuously in liquid medium with 2,4D. In this culture system, sectors of embryogenic tissue that express embryo reporter genes became visible at the shoot apex around 4-5 days of culture (Fig. 1a, b). By 14 days of culture, larger sectors of embryogenic tissue without defined polarity and bipolar somatic embryos were observed at the shoot apex (Fig. 1c, d) in ca. 20-50\% of the seedlings, depending on the seed batch. In general, explants developed embryogenic tissue and bipolar somatic embryos developed at a ratio of 3:1, regardless of the plant growth or culture conditions. Seedlings that did not form somatic embryos (non-embryogenic) did not show any additional growth at the shoot apex (Fig. 1c, d). The embryogenic structures developed without an apparent callus phase, suggesting that embryos develop by direct SE. Culture of mature arabidopsis seeds in liquid medium with 2,4-D is therefore an easy and reliable system for SE.

\section{Aged seeds have lower SE capacity}

During the course of analyses, we observed that the efficiency of somatic embryo induction, measured as the percent of embryogenic explants, differed from 20 to $50 \%$ depending on the seed batch. As this variability complicated 
Fig. 1 Somatic embryogenesis from germinating embryos. a A 4 day-old WOX2:NLS-YFP explant showing embryo marker expression (yellow) around the shoot apical meristem. C, cotyledon; SA shoot apex. Scale bar, $100 \mu \mathrm{m}$. b A 5 day-old ENODL4:GFP explant showing embryo marker expression (green) around the shoot apex. C, cotyledon; SA shoot apex. Scale bar, $250 \mu \mathrm{m}$. c A 14 dayold somatic embryo culture. Arrows and arrowheads indicate embryogenic tissue and somatic embryos, respectively. Scale bar, $5 \mathrm{~mm}$. d Non-embryogenic (left) and embryogenic (right) explants. Arrowheads indicate somatic embryos. Scale bars, $2.5 \mathrm{~mm}$. The explants in $\mathrm{a}$ and $\mathrm{b}$ were counter-stained with FM464 (red). a, b: confocal laser scanning microscopy images. c, d: light microscopy images. (Color figure online)
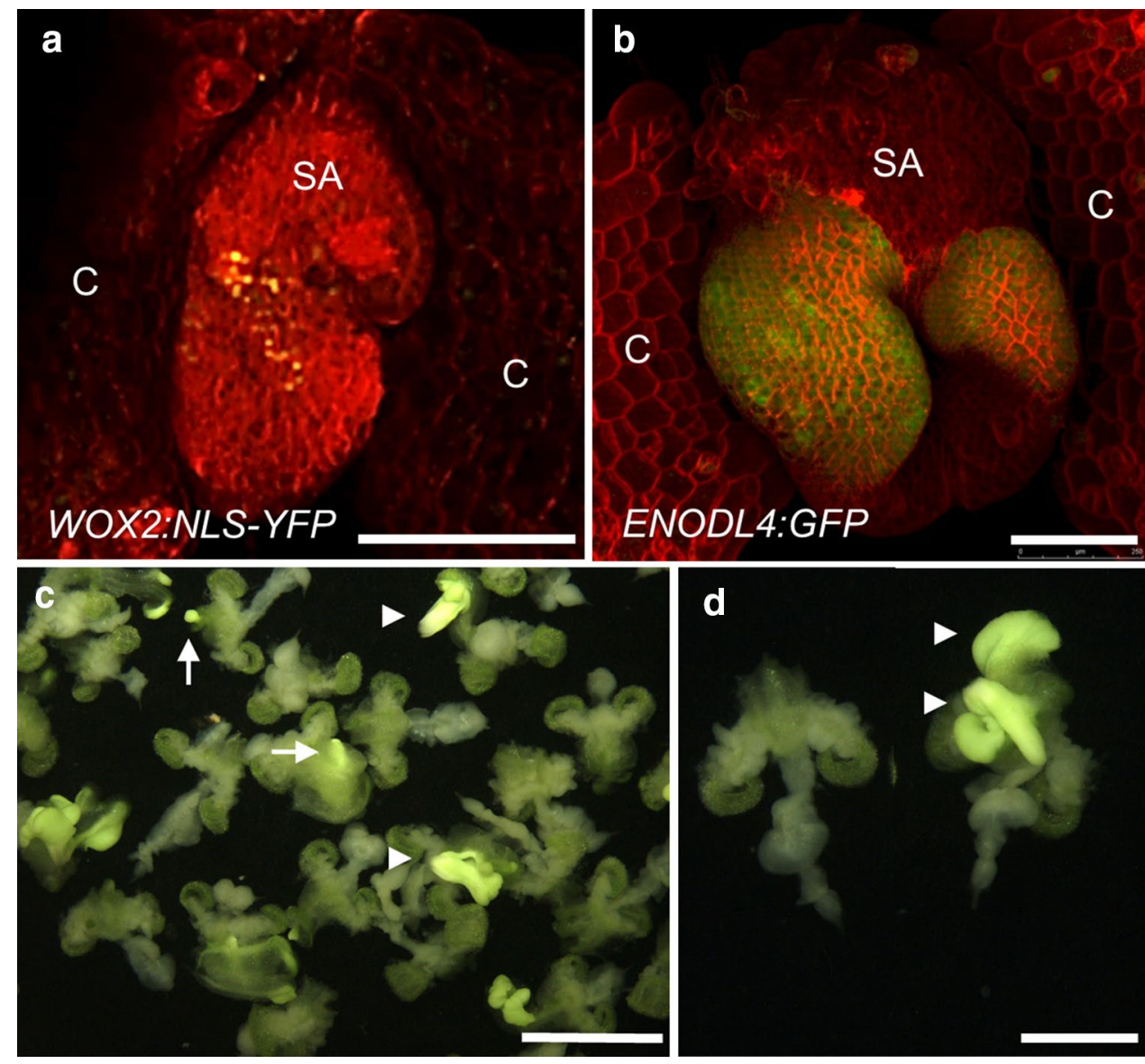

genetic and physiological studies, we determined whether differences in plant growth, seed harvest and seed storage conditions influenced the embryogenic capacity of seeds.

In our lab, seeds are often (inadvertently) harvested at different stages of maturity, therefore we determined whether the physiological age of the seed at the time of harvest influenced SE efficiency. We compared SE efficiency in seeds harvested when the first siliques had turned yellow (Materials and Methods) with seeds harvested 2 weeks later or longer, when all siliques had turned brown. Seeds at both stages have reached the late maturation phase of seed development, and both types of seeds were dried at $30 \%$ relative humidity. We observed that seeds harvested from yellow siliques were much more productive in somatic embryo culture than older seeds harvested from brown siliques (Fig. 2a). This suggests developmental processes take place during the progression of late seed maturation that reduce the ability of embryos to reinitiate embryo development at the shoot apex. Based on these results we used seed batches collected from yellow siliques for subsequent experiments.

The effect of plant growth and seed storage conditions on SE capacity was evaluated by making use of seed populations from plants grown under different temperatures and light conditions (He et al.2014) and stored immediately after drying at $-80^{\circ} \mathrm{C}$ (fresh) or on the lab bench at $20{ }^{\circ} \mathrm{C}$ for 5 years (aged). The major factor affecting SE efficiency was the post-harvest storage conditions, with freshly harvested seeds greatly outperforming aged seeds (Fig. 2b). Next, we examined the time frame in which post-harvest storage affects SE efficiency in seeds. Seeds collected from yellow siliques were dried at $30 \% \mathrm{RH}$ and stored for up to 60 days before initiating somatic embryo cultures. SE efficiency decreased in seeds between 30 and 60 days of storage (Fig. 2c). The timing of this decrease in SE efficiency is somewhat variable, as in other experiments, the decrease in efficiency could be observed a few weeks earlier or later (data not shown). The decrease in SE efficiency upon storage is not due to a reduction in seed quality as seed germination was $>95 \%$ for all seed batches.

Our results indicate that the physiological age of the seed at the time of harvest, as well as the post-harvest storage time are major factors influencing the capacity of seedlings to undergo SE. Physiologically younger seeds show an initially high SE capacity, which decreases with further storage, while physiologically older seeds have a lower capacity that does not decrease with further storage. This data implies that there is a narrow window in which seed physiology at the 
Fig. 2 Seed maturation and post-harvest storage negatively affect somatic embryogenesis efficiency. a Seeds harvested from yellow siliques show higher SE efficiency than those from brown siliques. Statistically-significant differences in SE efficiency were calculated using two-tailed Student's $t$ test $(* * p<0.01)$. Error bars represent the standard deviation. $n=3$. b The effect of plant growth conditions on SE efficiency. Seeds were collected from plants grown at different temperatures or under different light intensities (Supplemental Table 1; He et al. 2014) and the seeds stored at $-80{ }^{\circ} \mathrm{C}$ (fresh) or on the lab bench for ca. 5 years (aged). SC standard conditions; LL low light intensity; HL high light intensity. Statistically-significant differences in SE efficiency between fresh and aged seeds from the same condition were calculated using two-tailed Student's t-test $\left({ }^{* *} p<0.01\right)$. Error bars represent the standard deviation. $\mathrm{n}=3$. c SE efficiency drops quickly after seed harvest. A single batch of seeds from yellow siliques was harvested, dried at $30 \% \mathrm{RH}$ and then stored for the indicated number of days before being used for somatic embryo culture. SE efficiency was calculated after 2 weeks of culture. Seed germination was $100 \%$ for all treatments. Statistically-significant differences in SE efficiency were calculated using Fisher's Least Significant Difference test. Error bars represent the standard deviation. $n=3$

late maturation stage affects the capacity of the shoot apex to re-enter the embryo development pathway.

\section{ABA metabolism mutants have non-complementary roles in somatic embryogenesis}

Embryo development in arabidopsis and many other plants proceeds through three main phases, cell proliferation and morphogenesis, maturation and acquisition of desiccation. The maturation phase of seed development occurs toward the end of seed development in response to increasing levels of the hormone abscisic acid (ABA) and then decreases as the embryo loses water and enters a quiescent state (Leprince et al. 2016; Devic and Roscoe 2016). We examined whether ABA levels or degradation play a role in the decrease in somatic embryogenesis observed during seed maturation and storage, by examining the effect of ABA biosynthesis (nced6-1/nced 9-1) and catabolism (cyp707a1-1, cyp707a2-1) mutants on SE efficiency in fresh and aged seeds (He et al. 2014) (Fig. 3a). Freshly harvested nced6-1/nced9-1 seeds showed a significant decrease in SE efficiency compared to the WT seeds, but unlike WT seeds, did not show a decrease in SE efficiency after aging. The cyp $707 a$ mutants showed a WT level of somatic embryo induction in fresh seeds and decreased levels in aged seeds, although the cyp707al mutant showed a higher SE efficiency than the WT control, similar to the level observed in the nced6-1/nced9-1 seeds. Counterintuitively, both the nced6-1/nced9-1 biosynthesis mutant and the cyp707al catabolism mutant exhibited improved SE efficiency in aged seeds, therefore we examined the behavior of a second ABA biosynthesis mutant, aba2-1 (Leon-Kloosterziel et al. 1996) in somatic embryo culture from fresh to aged seeds (Fig. 3b). nced6/
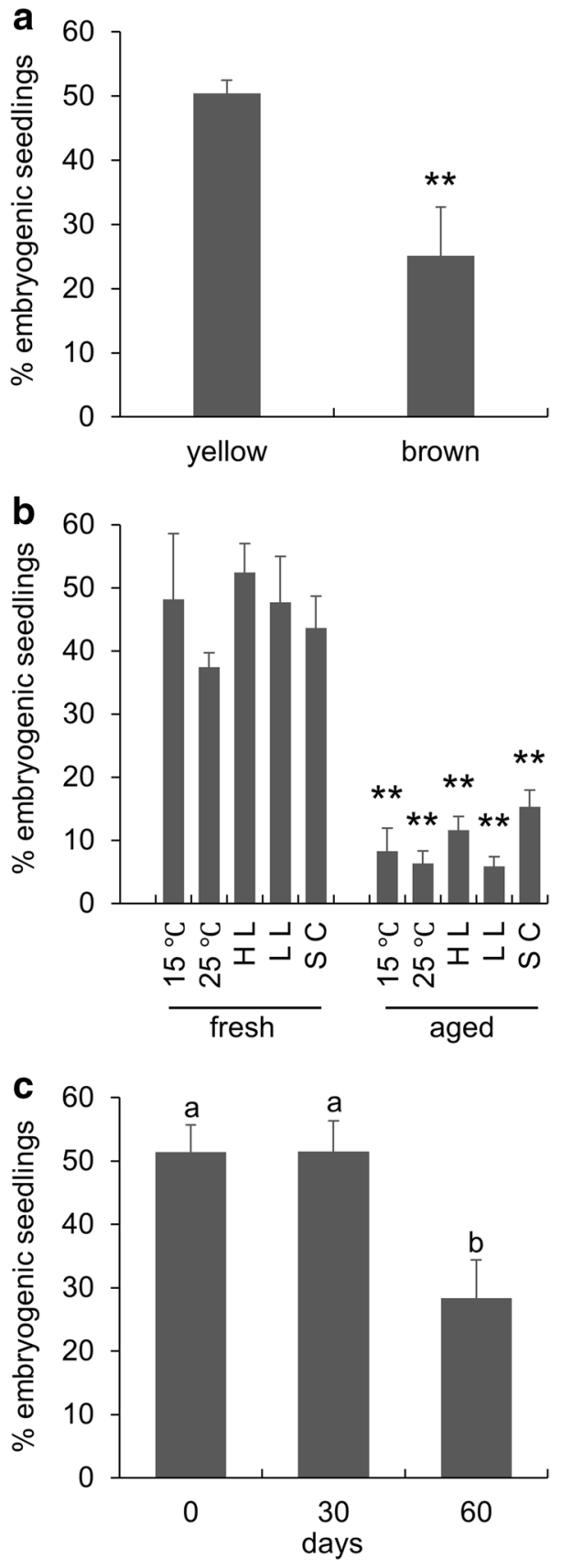

nced 9 double mutant plants have $33 \%$ less ABA than WT (Lefebvre et al. 2006), while the aba2-1 mutant rosettes have $80 \%$ less ABA than WT (Leon-Kloosterziel et al. 1996). Compared to WT seeds, SE efficiency was drastically reduced in fresh $a b a 2-1$ seeds harvested from yellow siliques, and although there was a trend toward reduced SE in aba2- 1 seeds after seed aging, the effect was not statistically significant (Fig. 3b). The already low SE response in $a b a 2-1$ seeds makes it difficult to interpret these results. We also determined whether addition of exogenous ABA to somatic embryo cultures could improve SE efficiency from seeds collected from brown siliques. 
Fig. 3 ABA metabolism and somatic embryo development from fresh and aged seeds. a Somatic embryo cultures were initiated using WT and mutant seeds. Seeds were harvested from yellow siliques, dried at $30 \% \mathrm{RH}$ and then stored at $-80{ }^{\circ} \mathrm{C}$ (fresh) or at room temperature (RT aged, $20^{\circ} \mathrm{C}$ ). The efficiency of somatic embryo formation was evaluated 14 days after the start of culture. The experiments were performed at the same time as those in Fig. 2, therefore the data for the wild-type Col-0 control seeds is the same in both experiments. Statistically-significant differences in SE efficiency were calculated using Fisher's Least Significant Difference test. Error bars represent the standard deviation. $n=3$. b Seeds collected from yellow siliques of WT and aba2-1 mutant plants were dried at 30\% RH and were used directly for SE culture (fresh) or after storage (aged) for 4 weeks at $4{ }^{\circ} \mathrm{C}$ or room temperature (RT; $20^{\circ} \mathrm{C}$ ). Statistically-significant differences in SE efficiency were calculated using Fisher's Least Significant Difference test. Error bars represent the standard deviation. $\mathrm{n}=3$. c Seeds harvested from WT brown siliques were cultured continuously with or without the indicated concentration of ABA. No statistically-significant differences were observed between the treatments. Error bars represent the standard deviation. $n=3$

Notably, addition of up to $1 \mu \mathrm{M}$ ABA did not improve SE efficiency of this explant (Fig. 3c). Higher ABA concentrations were not evaluated due to their negative effect on seed germination. The contradictory mutant phenotypes described above are difficult to explain, but suggest that although ABA generally is required for SE from germinating seeds, specific ABA pathway genes play different roles at different times during the process.

\section{Expression of ABA metabolism and seed maturation genes is not affected by post-harvest seed storage}

Increasing ABA levels mark the initiation of seed maturation program. Downstream of ABA biosynthesis and signaling is a complex network of transcription factors that controls the maturation phase of seed development, among which the LAFL transcription factors (for LEAFY COTYLEDON1 (LEC1), ABSCISIC ACID INSENSITIVE3 (ABI3), FUSCA3 (FUS3) and LEC2). These proteins direct seed maturation processes such as storage product accumulation and desiccation tolerance, but also have a role in the maintenance of embryo identity. The functions are also reflected in their overexpression phenotypes, where both storage product accumulation and embryo identity can be induced outside the seed (Devic and Roscoe 2016; Lepiniec et al. 2018). We examined whether changes in $L A F L$ gene expression might explain the differences in SE efficiency observed in freshly harvested and stored seeds using qRT-PCR analysis (Fig. 4). No differences in $L A F L$ gene expression were observed between freshly harvested and stored seeds, either at the start of culture or in the first 2 days of culture. Likewise, no differences were observed in CYP707A1 and CYP707A2 gene expression in fresh and aged seeds at the start or during the first few days of somatic embryo culture. This data
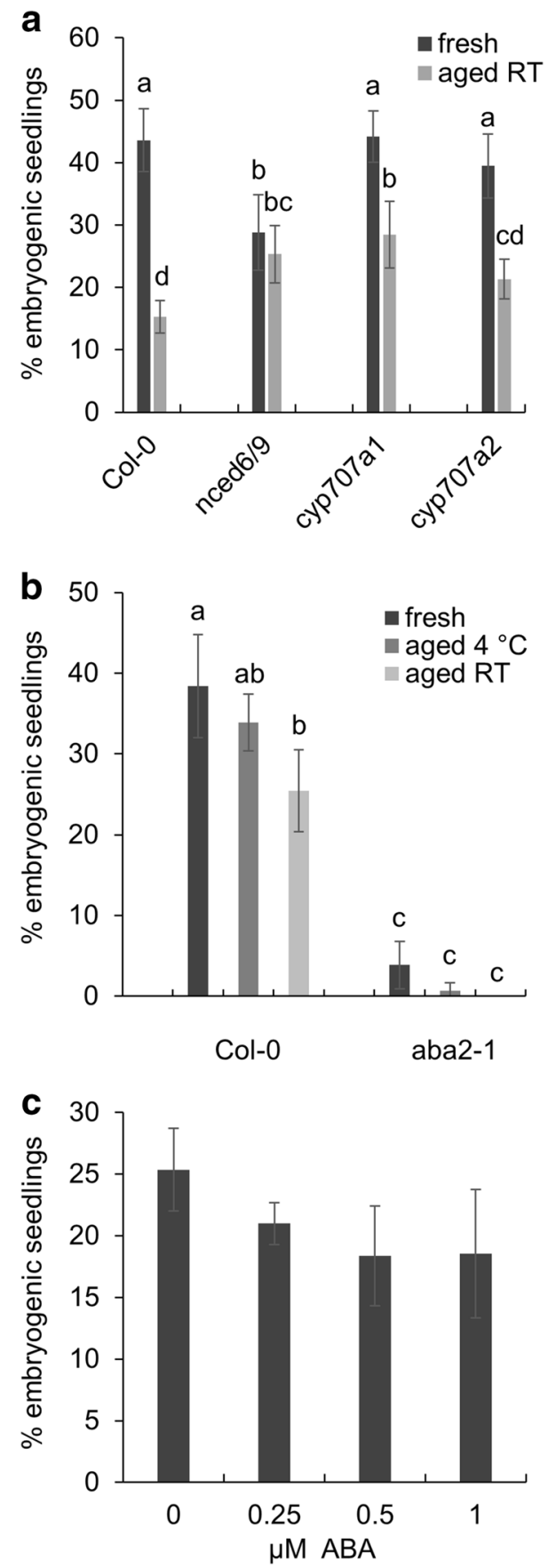

suggests that the effect of seed maturation and post-harvest seed storage on somatic embryogenesis are not attributable to changes in $L A F L$ gene expression.

\section{Oxidation during seed storage negatively affects somatic embryogenesis}

Seeds collected from yellow siliques and dried at $30 \%$ $\mathrm{RH}$ show a gradual reduction in their ability to form SEs after treatment with 2,4-D. Enzyme activity is inhibited at this low water content, but oxidation of molecules or 
Fig. 4 The expression levels of embryo maturation genes is not affected by seed storage. Relative expression levels of the indicated genes in fresh or stored seeds at the start of culture and 1- and 2-days after the start of somatic embryo culture. Relative expression levels were calculated using the $2^{-\Delta \Delta C_{T}}$ method using the $S A N D$ gene as reference and stored seeds as the calibrator. Error bars represent the standard deviation. $\mathrm{n}=3$
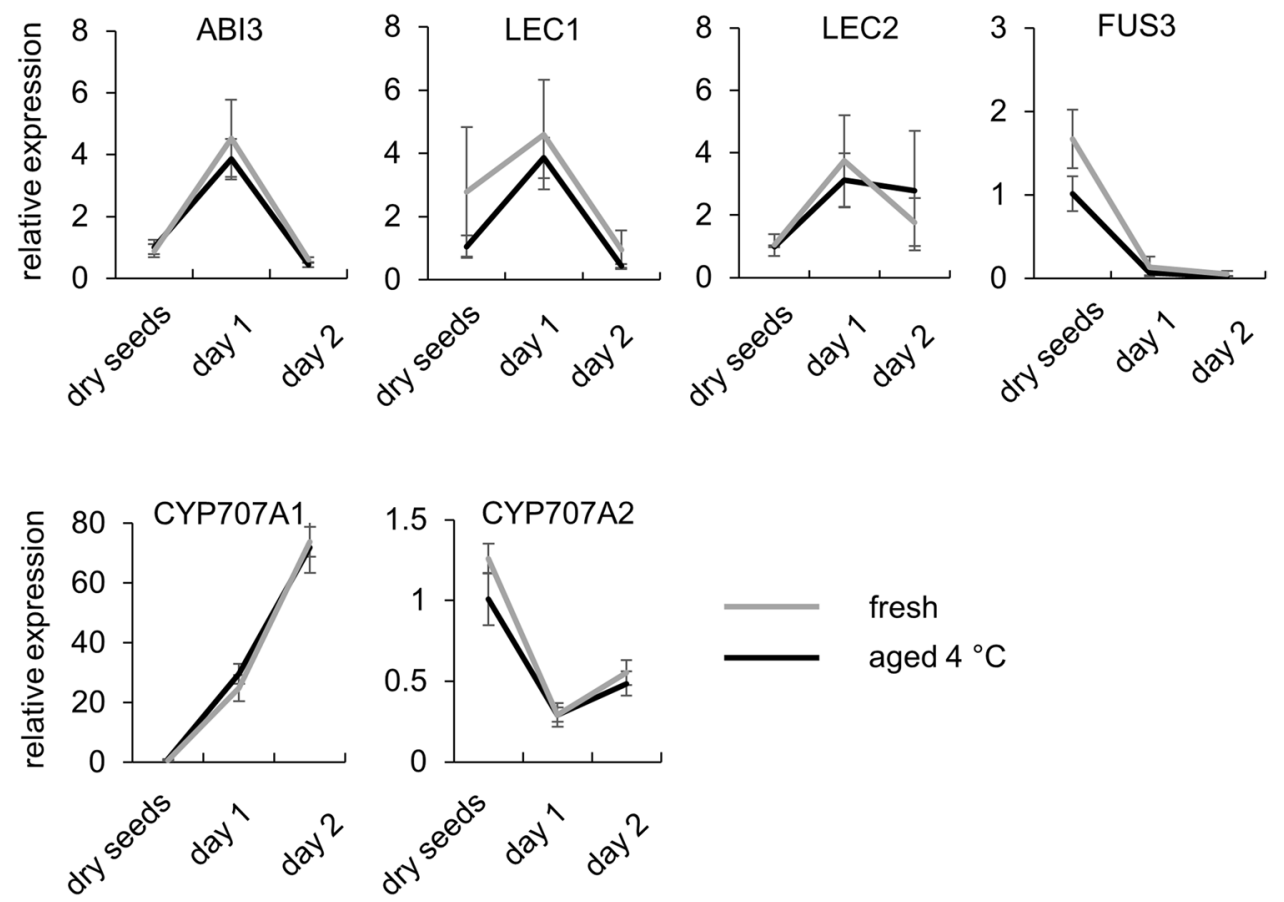

subcellular structures can still take place (Labuza and Dugan 1971). We therefore examined whether changes in oxidation levels might play a role in the decreased SE capacity observed during seed maturation and storage. Freshly harvested seeds from yellow siliques were dried at $30 \% \mathrm{RH}$ and stored in glass jars under $99 \% \mathrm{O}_{2}$ or in Eppendorf tubes at RT or $4{ }^{\circ} \mathrm{C}$ for different time periods before using them for somatic embryo culture (Fig. 5a). The high $\mathrm{O}_{2}$ treatment did not affect the total percent of germinated seeds. SE efficiency decreased in seeds stored under high $\mathrm{O}_{2}$ within 4 weeks of post-harvest storage, but was slower when seeds were stored under ambient $\mathrm{O}_{2}$ levels, whether at $4{ }^{\circ} \mathrm{C}$ or at ambient temperature. These data suggest that oxidation during seed storage is one factor that contributes to the reduction in embryogenic capacity in stored seeds.

Reactive oxygen species (ROS; e.g. $\mathrm{O}_{2}^{-}, \mathrm{H}_{2} \mathrm{O}_{2}, \mathrm{OH}^{*}$, ${ }^{1} \mathrm{O}_{2}$ ) are partially reduced or activated forms of atmospheric $\mathrm{O}_{2}$ that are formed as signaling molecules, as byproducts of metabolism and also under dry storage conditions in the presence of metal ions. We examined whether one of type of ROS, $\mathrm{H}_{2} \mathrm{O}_{2}$, which is formed during seed maturation and post-harvest storage (Bailly et al. 2008), affects the ability of germinating seeds to undergo SE. Exogenous $\mathrm{H}_{2} \mathrm{O}_{2}$ was added to $\mathrm{SE}$ cultures initiated from seeds harvested from yellow or brown siliques and that were dried at $30 \% \mathrm{RH}$. The $\mathrm{H}_{2} \mathrm{O}_{2}$ treatments did not affect the total proportion of germinated seeds. A drop in SE efficiency was observed after addition of only $0.5 \mathrm{mM}$ $\mathrm{H}_{2} \mathrm{O}_{2}$ for both types of seeds, but seeds from the more mature brown siliques were relatively less sensitive than less mature seeds from yellow siliques (Fig. 5b). Treatment of seeds with $0-1 \mathrm{mM} \mathrm{H}_{2} \mathrm{O}_{2}$ did not affect germination, but slightly delayed seedling growth, indicating that the reduction in SE is not due to a general negative effect of $\mathrm{H}_{2} \mathrm{O}_{2}$ on development (data not shown).

Taken together, these results indicate that an oxidative environment reduces the capacity of arabidopsis seeds to undergo SE, and by extension, that oxidative processes that take place during in planta seed development and post-harvest storage result in decreased SE efficiency.

\section{Discussion}

We examined the donor plant growth conditions and seed storage conditions as possible factors that could explain observed differences in SE efficiency from different batches of germinating arabidopsis Col-0 seeds. Our results indicate that the physiological state of the seed at the time of harvest, as well as the post-harvest storage time are the major factors influencing the capacity of germinating embryos to form somatic embryos. Physiologically younger seeds harvested from yellow siliques show an initially high SE capacity, which decreases with further storage, while physiologically older seeds harvested a few weeks later from brown siliques, have a lower SE capacity that does not decrease with further storage (Fig. 6). This data implies that there is a developmental window during late seed maturation that negatively affects the ability of the mature embryo to reenter the embryo development pathway, and that this process can be mimicked by seed storage. Notably, no significant 

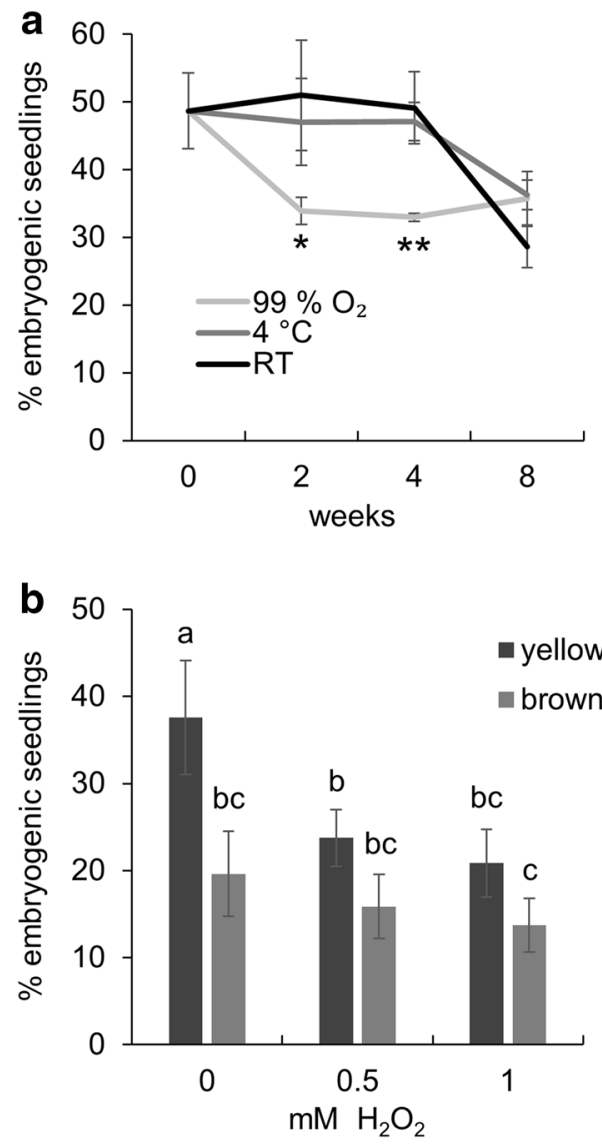

Fig. 5 Oxidation negatively affects somatic embryogenesis. a Seed storage under high oxygen accelerates the post-harvest decreases in SE efficiency. A single batch of seeds was harvested from yellow siliques, dried at $30 \% \mathrm{RH}$ and then stored (aged) under high $\mathrm{O}_{2}$ levels or in Eppendorf tubes at room temperature $\left(\mathrm{RT} ; 20^{\circ} \mathrm{C}\right)$ or $4{ }^{\circ} \mathrm{C}$ for the indicated time before being used for somatic embryo culture. Statisticallysignificant differences in SE efficiency between seeds stored at RT or seeds stored under high $\mathrm{O}_{2}$ or at $4{ }^{\circ} \mathrm{C}$ were calculated using two-tailed Student's t-test $(* p<0.05$, $* * p<0.01)$. Error bars represent the standard deviation. $\mathrm{n}=3 \mathbf{b ~ H}_{2} \mathrm{O}_{2}$ treatment reduces somatic embryogenesis efficiency. Seeds were harvested from yellow to brown siliques, dried at $30 \% \mathrm{RH}$ and used for somatic embryo culture. $\mathrm{H}_{2} \mathrm{O}_{2}$ was added before stratification at the indicated concentrations and then for the entire duration of the culture. Somatic embryogenesis was scored on day 14. Statistically-significant differences in SE efficiency were calculated using Fisher's Least Significant Difference test. Error bars represent the standard deviation. $\mathrm{n}=3$. (Color figure online)

differences were observed in the ratio of embryogenic tissue to bipolar embryos under any of the plant growth or culture conditions, or in any of the mutant lines.

Immature zygotic embryos (IZE) at the bent cotyledon stage (10-12 days after pollination, $>500 \mu \mathrm{m})$ are generally used as explants for somatic embryo culture, as these show the highest competence for SE, with up to $90 \%$ of the explants forming numerous somatic embryos upon continuous exposure to 2,4-D (Gaj 2004). Here, we showed that this competence decreases to ca. $40-50 \%$ when seeds seed maturation

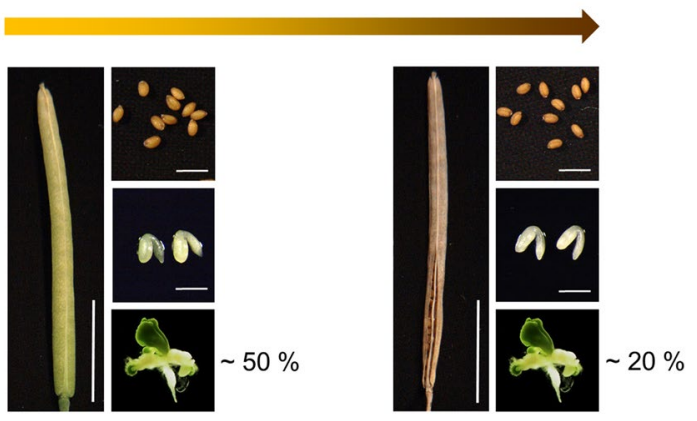

postharvest storage
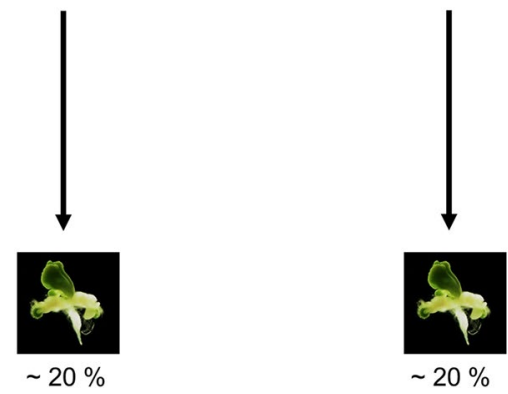

Fig. 6 Overview of the effect of seed maturation and post-harvest seed storage on 2,4-D induced somatic embryogenesis from germinating seeds. Two different late maturation seed explants are used for somatic embryo culture. Seeds from yellow siliques (left) and seeds from brown siliques (right). The effect of the starting material and post-harvest seed is shown as a $\%$ of the explants that develop somatic embryos. Scale bars for siliques, $5 \mathrm{~mm}$. Scale bars for seeds, $1 \mathrm{~mm}$. Scale bars for embryos, $0.5 \mathrm{~mm}$. (Color figure online)

with late maturation stage embryos from yellow siliques are used as explants (Fig. 6) and to $20-30 \%$ when seeds with late maturation stage embryos from brown siliques are used (Fig. 6). This data is in line with a previous study by Mozgová et al. (2017), who also observed a decline in the capacity for 2,4-D-induced indirect SE during the course of seed development. We show that seed drying per se does not reduce the competence for SE in late maturation stage seeds, as seeds collected from yellow siliques show the same capacity for $\mathrm{SE}$ when placed immediately in culture or when dried at $30 \% \mathrm{RH}$. In general there is a gradual decrease in the competence of zygotic embryos for 2,4-D induced SE during the seed maturation phase, that is not related to the water content of the seed.

What are other seed maturation and storage factors that might contribute to the observed reduction in embryogenic competence in seeds harvested from yellow to brown siliques? Embryo development in arabidopsis can be divided into three main phases: cell proliferation, morphogenesis and maturation (Baud et al. 2002; ten Hove et al. 2015). The embryo explants used for arabidopsis somatic embryogenesis are all in the maturation phase of development, the last stage of seed development. The maturation phase 
begins with a shift from cell division to cell expansion, during which large amount of storage products accumulate in the embryo (Santos-Mendoza et al. 2008), and ends with the late maturation phase in which chlorophyll and carotenoid breakdown, raffinose family oligosaccharide (RFO) accumulation, synthesis of protective proteins, and the acquisition of desiccation tolerance all take place (Leprince et al. 2016; Jalink et al. 1998; Soeda et al. 2005; Nguyen et al. 2015). Longevity, or the ability of the seed to remain viable for long periods, is also established during late maturation (Sano et al. 2016). The two types of seed explants used in this study have already acquired desiccation tolerance and can be stored for long periods, indicating that they have reached the late maturation phase of development. Nonetheless, they differ in their competence for somatic embryogenesis, suggesting that additional changes take place during a narrow window at the end of the late maturation phase in planta or post-harvest influence their ability to re-enter the embryo development pathway.

The plant hormone ABA directs seed maturation processes including storage product accumulation and dormancy acquisition (Yan and Chen 2017). ABA can induce SE in some systems and has also been implicated as a downstream component of 2,4-D induced SE, particularly in the context of a 2,4-D-induced stress response (Fehér 2015). The role of ABA in arabidopsis SE has been investigated, but the results differ depending on the explant, the type of SE (direct or indirect via a callus phase) and the inducer treatment. During direct SE derived from IZEs, both ABA insensitive and hypersensitive mutants have a negative effect on SE, while the process is not affected greatly by ABA biosynthesis mutants (Gaj et al. 2006). Treatment of embryogenic callus with fluridone, a carotenoid biosynthesis inhibitor, has a negative effect on secondary SE from IZEderived embryogenic callus, which can be complemented by addition of exogenous ABA (Su et al. 2013). Our results show that ABA biosynthesis is important for SE from germinating seeds, based on the reduced efficiency of the nced6/9 and aba2-1 mutants. However, it is not clear how ABA plays a role in mitigating the negative effect of seed maturation and seed storage on SE from germinating seeds. Firstly, in apparent contradiction, both the nced6/nced 9 biosynthesis and cyp707al catabolism mutants, with respectively lower and higher seed ABA levels, can (partially) rescue the negative effect of seed aging on SE. Secondly, addition of exogenous ABA to SE cultures of germinating seeds from aged seeds did not improve SE efficiency to the level observed in germinating seeds from younger (yellow) siliques. These data, as well as those of Gaj et al. (2006) on the effect of ABA mutants on IZE somatic embryo culture, point to a complex role for $\mathrm{ABA}$ in $\mathrm{SE}$, where $\mathrm{ABA}$-related processes might have roles at different time points throughout somatic embryo culture. Whether the effects of the ABA metabolism mutants used in this study on SE are direct or indirect needs to be determined, but at least one downstream component of ABA signaling, $L A F L$ gene expression, did not show early differential regulation between somatic embryo cultures from fresh and aged seeds.

Preliminary experiments suggest that seed storage under oxidative conditions or treatment with $\mathrm{H}_{2} \mathrm{O}_{2}$ can mimic the decrease in SE efficiency observed as seeds ripen through the end of the late maturation phase or upon storage of incompletely ripened seeds. ROS production regulates many developmental processes, as well as abiotic and biotic stress responses, but when ROS production is untimely or excessive it can also induce cell damage, for instance by oxidizing DNA, RNA and protein molecules, as well as subcellular structures such as membranes (Cheah and Osborne 1978; Sewelam et al. 2016; Mhamdi and Van Breusegem 2018). ROS production occurs during embryo maturation as part of normal development and is kept in balance by LEA proteins and ROS scavenging enzymes (Bailly 2004; Cairns et al. 2006), but have been studied mainly in the context of seed dormancy, germination and longevity (Delahaie et al. 2013; Pehlivan 2017). ROS are produced in seeds during postharvest storage, and can be required to release dormancy and promote germination, but when storage conditions are unfavorable, can exert negative effects on longevity and seedling vigor (Bailly et al. 2008; Petla et al. 2016; Ishibashi et al. 2017). A common signaling mechanism linking late maturation and post-harvest seed storage outside of the context of dormancy, germination and longevity has not been described. In our experiments, the proportion of germinated seeds was not affected by seed storage under high oxygen conditions or after treatment with $\mathrm{H}_{2} \mathrm{O}_{2}$ suggesting that these treatments affected a novel, as of yet unknown, developmental process.

This study opens up the possibility for targeted screens to identify enhancers and suppressors of SE in seeds collected at different developmental time points of the late maturation phase. A number of factors were found to affect SE efficiency during the late maturation phase, including seed ABA metabolism and ROS, while other potential differences between early and late maturation seeds, including differences in levels of ROS-protective carotenoids, RFOs, nuclear size/DNA condensation (Zanten et al. 2014), and chromatin-mediated repression of embryo identity genes (Mozgová et al. 2017), and are potential targets for future research.

Germinating embryos are used as explants for somatic embryo induction in a wide range of species (Steinitz et al. 2003; Rosa et al. 2015; Cabral et al. 2016; San Pedro et al. 2017; Kashyap et al. 2018), in part because they are easier to collect and store than other types of explants and generally require less handling. Our observations that the efficiency of arabidopsis SE is affected significantly by small differences in the time of seed harvest, as well as the post-harvest 
storage period, highlights the important contribution of plant growth conditions to the development of efficient SE protocols that use mature seeds as explants. The knowledge gained in the model plant arabidopsis can now be used as a starting point to optimize mature seed embryo culture in other species.

Acknowledgements This work was supported by a China Scholarship Council Fellowships to B. C and H. W. and a Netherlands Genomic Initiative Horizon grant to M.F. We thank Leo Willems for preparing plant materials.

Author contributions B.C., K.B., G.A., L.B., M.F. and S.G. designed experiments. B.C., H.W., J.K., J.W-M. and M.F. performed experiments. B.C. and K.B. wrote- and all authors provided feedback on the manuscript.

Open Access This article is distributed under the terms of the Creative Commons Attribution 4.0 International License (http://creativeco mmons.org/licenses/by/4.0/), which permits unrestricted use, distribution, and reproduction in any medium, provided you give appropriate credit to the original author(s) and the source, provide a link to the Creative Commons license, and indicate if changes were made.

\section{References}

Arrillaga I, Morcillo M, Zanón I et al (2019) New approaches to optimize somatic embryogenesis in maritime pine. Front Plant Sci 10:138. https://doi.org/10.3389/fpls.2019.00138

Bailly C (2004) Active oxygen species and antioxidants in seed biology. Seed Sci Res 14:93-107. https://doi.org/10.1079/SSR2004159

Bailly C, El-Maarouf-Bouteau H, Corbineau F (2008) From intracellular signaling networks to cell death: the dual role of reactive oxygen species in seed physiology. C R Biol 331:806-814. https ://doi.org/10.1016/j.crvi.2008.07.022

Bartolotta A, Caputo V, Galletta M, et al (1991) Equilibrium moisture content and dynamic behaviour of some types of silica gel. In NS Baer, C Sabbioni, AI Sors (eds) Science, technology and european cultural heritage. Butterworth-Heinemann. Proceedings of the European Symposium, Bologna, Italy, 13-16 June 1989, p 731-734. https://doi.org/10.1016/b978-0-7506-0237-2.50130-1

Baud S, Boutin J-P, Miquel M et al (2002) An integrated overview of seed development in Arabidopsis thaliana ecotype WS. Plant Physiol Biochem 40:151-160. https://doi.org/10.1016/S0981 -9428(01)01350-X

Bensen EA (2000) In vitro plant recalcitrance: an introduction. In Vitro Cell Dev Biol Plant 36(3):141-148

Bonga JM (2017) Can explant choice help resolve recalcitrance problems in in vitro propagation, a problem still acute especially for adult conifers? Trees 31:781-789. https://doi.org/10.1007/s0046 8-016-1509-z

Breuninger H, Rikirsch E, Hermann M et al (2008) Differential expression of WOX genes mediates apical-basal axis formation in the Arabidopsis embryo. Dev Cell 14:867-876. https://doi. org/10.1016/j.devcel.2008.03.008

Bridgen MP, Van Houtven W, Eeckhaut T (2018) Plant tissue culture techniques for breeding. Springer, Cham, pp 127-144

Cabral GB, Carneiro VTC, Dusi DMA, Martinelli AP (2016) Somatic embryogenesis and plant regeneration of Brachiaria brizantha. Methods Mol Biol (Clifton) 1359:395-402

Cairns NG, Pasternak M, Wachter A, Cobbett CS, Meyer AJ (2006) Maturation of arabidopsis seeds is dependent on glutathione biosynthesis within the embryo. Plant Physiol 41:446-455. https ://doi.org/10.1104/pp.106.077982

Cheah KSE, Osborne DJ (1978) DNA lesions occur with loss of viability in embryos of ageing rye seed. Nature 272:593-599

Czechowski T, Stitt M, Altmann T et al (2005) Genome-wide identification and testing of superior reference genes for transcript normalization in Arabidopsis. Plant Physiol 139:5-17. https://doi. org/10.1104/pp.105.063743

de Folter S, Urbanus SL, van Zuijlen LGC et al (2007) Tagging of MADS domain proteins for chromatin immunoprecipitation. BMC Plant Biol 7:47. https://doi.org/10.1186/1471-2229-7-47

Delahaie J, Hundertmark M, Bove J et al (2013) LEA polypeptide profiling of recalcitrant and orthodox legume seeds reveals ABI3regulated LEA protein abundance linked to desiccation tolerance. J Exp Bot 64:4559-4573. https://doi.org/10.1093/jxb/ert274

Devic M, Roscoe T (2016) Seed maturation: simplification of control networks in plants. Plant Sci 252:335-346. https://doi. org/10.1016/J.PLANTSCI.2016.08.012

Dwivedi SL, Britt AB, Tripathi L et al (2015) Haploids: constraints and opportunities in plant breeding. Biotechnol Adv 33:812-829. https://doi.org/10.1016/j.biotechadv.2015.07.001

Fehér A (2015) Somatic embryogenesis-stress-induced remodeling of plant cell fate. Biochim Biophys Acta Gene Regul Mech 1849:385-402. https://doi.org/10.1016/j.bbagrm.2014.07.005

Gaj MD (2004) Factors influencing somatic embryogenesis induction and plant regeneration with particular reference to Arabidopsis thaliana (L.) Heynh. Plant Growth Regul 43:27-47. https://doi. org/10.1023/B:Grow.0000038275.29262.Fb

Gaj MD, Trojanowska A, Ujczak A et al (2006) Hormone-response mutants of Arabidopsis thaliana (L.) Heynh. impaired in somatic embryogenesis. Plant Growth Regul 49:183-197. https://doi. org/10.1007/s10725-006-9104-8

Grafi G (2004) How cells dedifferentiate: a lesson from plants. Dev Biol 268:1-6. https://doi.org/10.1016/j.ydbio.2003.12.027

Groot SPC, Surki AA, de Vos RCH et al (2012) Seed storage at elevated partial pressure of oxygen, a fast method for analysing seed ageing under dry conditions. Ann Bot 110:1149-1159. https://doi. org/10.1093/aob/mcs 198

Grzyb M, Kalandyk A, Waligórski P, Mikuła A (2017) The content of endogenous hormones and sugars in the process of early somatic embryogenesis in the tree fern Cyathea delgadii Sternb. Plant Cell, Tissue Organ Cult 129:387-397. https://doi.org/10.1007/ s11240-017-1185-8

He H, de Souza Vidigal D, Snoek LB et al (2014) Interaction between parental environment and genotype affects plant and seed performance in Arabidopsis. J Exp Bot 65:6603-6615. https://doi. org/10.1093/jxb/eru378

Hisano H, Matsuura T, Mori IC et al (2016) Endogenous hormone levels affect the regeneration ability of callus derived from different organs in barley. Plant Physiol Biochem 99:66-72. https://doi. org/10.1016/j.plaphy.2015.12.005

Horstman A, Bemer M, Boutilier K (2017) A transcriptional view on somatic embryogenesis. Regeneration 4(4):201-216. https://doi. org/10.1002/reg2.91

Ikeda-Iwai M, Satoh S, Kamada H (2002) Establishment of a reproducible tissue culture system for the induction of Arabidopsis somatic embryos. J Exp Bot 53:1575-1580. https://doi.org/10.1093/jxb/ erf006

Ikeda-Iwai M, Umehara M, Satoh S, Kamada H (2003) Stress-induced somatic embryogenesis in vegetative tissues of Arabidopsis thaliana. Plant J 34:107-114. https://doi.org/10.1046/j.1365313X.2003.01702.x

Ikeuchi M, Ogawa Y, Iwase A, Sugimoto K (2016) Plant regeneration: cellular origins and molecular mechanisms. Development 143:1442-1451. https://doi.org/10.1242/dev.134668 
Ishibashi Y, Aoki N, Kasa S et al (2017) The interrelationship between abscisic acid and reactive oxygen species plays a key role in barley seed dormancy and germination. Front Plant Sci 8:275. https://doi. org/10.3389/fpls.2017.00275

Jalink H, van der Schoor R, Frandas A, van Pijlen JG (1998) Chlorophyll fluorescence of Brassica oleracea seeds as a non-destructive marker for seed maturity and seed performance. Seed Sci Res 8:437-443. https://doi.org/10.1017/S0960258500004402

Kareem A, Radhakrishnan D, Sondhi Y et al (2016) De novo assembly of plant body plan: a step ahead of deadpool. Regeneration 3:182-197. https://doi.org/10.1002/reg2.68

Kashyap A, Penak SM, Saha A, Singh BR (2018) In vitro plant development of Eleusine coracana via indirect organogenesis and somatic embryogenesis using mature seeds as explants. Curr Sci 115:91-98. https://doi.org/10.18520/CS/V115/I1/91-98

Kobayashi T, Nagayama Y, Higashi K, Kobayashi M (2010) Establishment of a tissue culture system for somatic embryogenesis from germinating embryos of Arabidopsis thaliana. Plant Biotechnol 27:359-364. https://doi.org/10.5511/plantbiotechnology.27.359

Kushiro T, Okamoto M, Nakabayashi K et al (2004) The arabidopsis cytochrome P450 CYP707A encodes ABA 8'-hydroxylases: key enzymes in ABA catabolism. EMBO 23:1647-1656. https://doi. org/10.1038/sj.emboj.7600121

Labuza TP, Dugan LR (1971) Kinetics of lipid oxidation in foods. Crit Rev Food Technol 2:355-405. https://doi.org/10.1080/10408 397109527127

Lefebvre V, North H, Frey A et al (2006) Functional analysis of Arabidopsis NCED6 and NCED9 genes indicates that ABA synthesized in the endosperm is involved in the induction of seed dormancy. Plant J 45:309-319. https://doi.org/10.1111/j.1365313X.2005.02622.x

Leon-Kloosterziel KM, Gil MA, Ruijs GJ et al (1996) Isolation and characterization of abscisic acid-deficient Arabidopsis mutants at two new loci. Plant J 10:655-661. https://doi.org/10.1046/j.1365313X.1996.10040655.X

Lepiniec L, Devic M, Roscoe TJ et al (2018) Molecular and epigenetic regulations and functions of the LAFL transcriptional regulators that control seed development. Plant Reprod 3:291-307. https:// doi.org/10.1007/s00497-018-0337-2

Leprince O, Pellizzaro A, Berriri S, Buitink J (2016) Late seed maturation: drying without dying. J Exp Bot 68:827-841. https://doi. org/10.1093/jxb/erw363

Li H, Soriano M, Cordewener J et al (2014) The histone deacetylase inhibitor trichostatin a promotes totipotency in the male gametophyte. Plant Cell 26:195-209. https://doi.org/10.1105/ tpc.113.116491

Livak KJ, Schmittgen TD (2001) Analysis of relative gene expression data using real-time quantitative PCR and the $2^{-\Delta \Delta C T}$ method. Methods 25:402-408. https://doi.org/10.1006/meth.2001.1262

Lowe BA, Way MM, Kumpf JM et al (2006) Marker assisted breeding for transformability in maize. Mol Breed 18:229-239. https://doi. org/10.1007/s11032-006-9031-4

Luo Y, Koop HU (1997) Somatic embryogenesis in cultured immature zygotic embryos and leaf protoplasts of Arabidopsis thaliana ecotypes. Planta 202:387-396

Méndez-Hernández HA, Ledezma-Rodríguez M, Avilez-Montalvo RN et al (2019) Signaling overview of plant somatic embryogenesis. Front Plant Sci 10:77. https://doi.org/10.3389/fpls.2019.00077

Mhamdi A, Van Breusegem F (2018) Reactive oxygen species in plant development. Development. https://doi.org/10.1242/dev.164376

Mordhorst AP, Voerman KJ, Hartog MV et al (1998) Somatic embryogenesis in Arabidopsis thaliana is facilitated by mutations in genes repressing meristematic cell divisions. Genetics 149:549-563

Motte H, Vercauteren A, Depuydt S et al (2014) Combining linkage and association mapping identifies RECEPTOR-LIKE PROTEIN KINASE1 as an essential Arabidopsis shoot regeneration gene.
Proc Natl Acad Sci 111:8305-8310. https://doi.org/10.1073/ pnas. 1404978111

Mozgová I, Muñoz-Viana R, Hennig L (2017) PRC2 Represses hormone-induced somatic embryogenesis in vegetative tissue of Arabidopsis thaliana. PLoS Genet 13:e1006562. https://doi. org/10.1371/journal.pgen.1006562

Murashige T, Skoog F (1962) A revised medium for rapid growth and bioassays with tobacco tissue cultures. Plant Physiol 15:473-497

Nguyen TP, Cueff G, Hegedus DD et al (2015) A role for seed storage proteins in Arabidopsis seed longevity. J Exp Bot 66:6399-6413. https://doi.org/10.1093/jxb/erv348

Pehlivan FE (2017) Free radicals and antioxidant system in seed biology. In: Advances in seed biology. InTech, pp 176-183. https:// doi.org/10.5772/intechopen.70837

Petla BP, Kamble NU, Kumar M et al (2016) Rice PROTEIN 1-ISOASPARTYL METHYLTRANSFERASE isoforms differentially accumulate during seed maturation to restrict deleterious isoAsp and reactive oxygen species accumulation and are implicated in seed vigor and longevity. New Phytol 211:627-645. https://doi.org/10.1111/nph.13923

Rosa YBCJ, Bello CCM, Dornelas MC (2015) Species-dependent divergent responses to in vitro somatic embryo induction in Passiflora spp. Plant Cell, Tissue Organ Cult 120:69-77. https://doi. org/10.1007/s11240-014-0580-7

San Pedro T, Gammoudi N, Peiró R et al (2017) Somatic embryogenesis from seeds in a broad range of Vitis vinifera L. varieties: rescue of true-to-type virus-free plants. BMC Plant Biol 17:226. https://doi.org/10.1186/s12870-017-1159-3

Sano N, Rajjou L, North HM et al (2016) Staying alive: molecular aspects of seed longevity. Plant Cell Physiol 57:660-674. https:// doi.org/10.1093/pcp/pcv186

Santos-Mendoza M, Dubreucq B, Baud S et al (2008) Deciphering gene regulatory networks that control seed development and maturation in Arabidopsis. Plant J 54:608-620. https://doi.org/10.1111/ j.1365-313X.2008.03461.x

Sewelam N, Kazan K, Schenk PM (2016) Global plant stress signaling: reactive oxygen species at the cross-road. Front Plant Sci 7:187. https://doi.org/10.3389/fpls.2016.00187

Soeda Y, Konings MC, Vorst O, van Houwelingen AM et al (2005) Gene expression programs during Brassica oleracea seed maturation, osmopriming, and germination are indicators of progression of the germination process and the stress tolerance level. Plant Physiol 137:354-368. https://doi.org/10.1104/pp.104.051664

Steinitz B, Küsek M, Tabib Y et al (2003) Pepper (Capsicum annuиm L.) regenerants obtained by direct somatic embryogenesis fail to develop a shoot. Vitro Cell Dev Biol Plant 39:296-303. https:// doi.org/10.1079/IVP2002405

Su YH, Su YX, Liu YG, Zhang XS (2013) Abscisic acid is required for somatic embryo initiation through mediating spatial auxin response in Arabidopsis. Plant Growth Regul 69:167-176. https ://doi.org/10.1007/s10725-012-9759-2

ten Hove CA, Lu K-J, Weijers D (2015) Building a plant: cell fate specification in the early Arabidopsis embryo. Development 142:420-430. https://doi.org/10.1242/dev.111500

van Zanten M, Zöll C, Wang Z et al (2014) HISTONE DEACETYLASE 9 represses seedling traits in Arabidopsis thaliana dry seeds. Plant J 80:475-488. https://doi.org/10.1111/tpj.12646

Wójcikowska B, Gaj MD (2016) Somatic embryogenesis in Arabidopsis. Somatic embryogenesis: fundamental aspects and applications. Springer, Cham, pp 185-199

Yan A, Chen Z (2017) The pivotal role of abscisic acid signaling during transition from seed maturation to germination. Plant Cell Rep 36:689-703. https://doi.org/10.1007/s00299-016-2082-z

Publisher's Note Springer Nature remains neutral with regard to jurisdictional claims in published maps and institutional affiliations. 